\title{
Elena Ovchinnikova
}

http://orcid.org/0000-0003-3090-4580

Państwowy Uniwersytet w Sankt Petersburgu

ovchinnikovaea@mail.ru

Sergey Troitskiy

http://orcid.org/0000-0002-2663-3629

Państwowy Uniwersytet w Sankt Petersburgu sergtroy@yandex.ru

DOI: $10.35765 /$ pk.2021.3403.03

\section{Identyfikacja genderowa w rosyjskim dyskursie kulturowym.}

\section{Od średniowiecza po oświecenie ${ }^{1}$}

\section{STRESZCZENIE}

Tematem artykułu jest proces transformacji wyobrażeń o genderowej tożsamości przedstawiony na przykładzie rosyjskiej kultury od XVI do początków XVIII w. Głównym celem pracy jest analiza i opis specyfiki ówczesnych wyobrażeń na temat cech płciowych mężczyzny i kobiety, a także procesu stanowienia autonomicznego dyskursu żeńskiego. Zdaniem autorów niniejszego badania, tożsamość mężczyzny i kobiety z punktu widzenia przynależności do domu (rodu, rodziny) jako całości, właściwa dla kultury tradycyjnej, nie zakładała samodzielnej genderowej tożsamości, a jedynie tożsamość funkcjonalną. Jednocześnie, utrwalenie funkcji żony oraz męża, jak również służących i dzieci (Domoustroj), prowadziło do tego, że obyczaj uzyskał charakter normatywny, na skutek czego każda z takich funkcji uzyskała samodzielność w świetle prawa. Z jednej strony czyni to możliwym przeniesienie trójczłonowej struktury domu (jako systemu powiązanych funkcji ojca, żony oraz dzieci/służących) na inne społeczno-kulturowe fenomeny, jak choćby na państwo, przykładem czego są idee A. Kurbskiego (państwo jako trójczłonowa relacja car - doradcy - naród). Zarazem staje się możliwe rozpatrywanie poszczególnych funkcji w oderwaniu od płci lub całkowite pominięcie niektórych funkcji w systemie społecznym. Przykładem tego jest podejście reprezentowane przez cara Iwana Groźnego, chociaż ogólnie zachowuje on jeszcze tradycyjne wzorce generujące sensy kulturowe, postrzegając państwo

1 Przekład z języka rosyjskiego wykonał Roman Turowski. Oryginalny artykuł: Ovchinnikova, E. i Troitskiy, S. (2019). Gendernaya identifikatsiya v rossiyskom kul'turnom diskurse: ot srednevekov'ya $\mathrm{k}$ prosveshcheniyu. Zhenshchina $v$ rossiyskom obshchestve, $\mathrm{nr} 4,100-112$. DOI: $10.21064 /$ WinRS.2019.4.9.

Sugerowane cytowanie: Ovchinnikova, E. i Troitskiy, S. (2021). Identyfikacja genderowa w rosyjskim dyskursie kulturowym. Od średniowiecza po oświecenie. @ (i) Perspektywy Kultury, 3(34), ss. 21-38. DOI: 10.35765/pk.2021.3403.03. 
jako dwuczłonową strukturę car - poddani. Usamodzielnienie funkcji społecznych w dalszej perspektywie czasowej pozwala na kształtowanie niezależnych żeńskich obrazów w XVII w. - w postaci czy to nauczających działaczek religijnych, jak Morozowa lub Urusowa, czy też księżnej Sofii. Następnie, już na początku wieku XVIII, miało dojść do całkowitego przeformatowania sfery kulturowej - od tego momentu można mówić o samodzielnym żeńskim dyskursie, jak również o dyskursie męskim. W drugiej połowie XVIII w. mężczyzna i kobieta są już postrzegani w ramach dwóch autonomicznych - żeńskiego i męskiego - dyskursów, chociaż M. Szczerbatow uznaje taką tendencję za skutek upadku obyczajów.

SŁOWA KLUCZE: tożsamość genderowa, kultura rosyjska, dyskurs kulturowy, kobieta, mężczyzna, Domoustrój, dyskurs żeński

\section{ABSTRACT}

Gender Identification in the Russian Cultural Discourse. From the Middle Ages to Enlightenment

The article examines the process of transformation of ideas about gender identity on the material of Russian culture 16th and the beginning of the 18 th century. The main goal of the work is the analysis and description of differences in the concept of gender and age characteristics, as well as the description and analysis of the process of the formation of female discourse as independent. According to the authors of the study, the identification of a man and a woman from the point of view of belonging to the home (gender, family) as a whole, which is belong to traditional culture, does not imply an independent gender identity, but only a functional one. At the same time, the fixation of the functions of the wife and husband, as well as servants and children ("Domostroy") leads to the fact that the custom acquires a normative character and, as a result, each of the functions acquires legal independence, which makes it possible, on the one hand, to transfer the structure of the home (as the relationship of functions) to other cultural phenomena (for example, the state), as A. Kurbsky does, and on the other hand, suppose the independence of individual functions, the possibility of their absence in the system, the features of such point of view are demonstrated by Ivan IV, although on the whole they retain traditional semantic patterns. But it is this approach that allows independent female images to emerge in the 17th century in the person of the teachers of the schismatic Morozova and Urusova or princess Sophia. At the beginning of the 18th century, a complete reformatting of the cultural sphere takes place and one can speak of an independent female discourse, like the male one. In the second half of the 18 th century, a man and a woman were already 
perceived separately, although, for example, for M. Shcherbatov it was the result of damage to morals.

KEYWORDS : gender identity, Russian culture, cultural discourse, woman, man, Domostroy, women's discourse

Tradycyjna forma tożsamości, której odbicie można odnaleźć w rosyjskich źródłach pisemnych z okresu przedpiotrowskiego, sprowadza się ku topograficznemu myśleniu o podmiocie. Inaczej mówiąc, podmiot prawnego, gospodarczego oraz etycznego dyskursu definiowano w czasach przed Piotrem I przede wszystkim na podstawie jego usytuowania w przestrzeni [społecznej - tłum.]. Dokładniej ujmując, głównym wskaźnikiem jego istnienia jest odpowiednia reprezentacja przestrzenna. Należy podkreślić, że nie chodzi o cielesność podmiotu, która występuje raczej jako marker podmiotu, nie wyczerpując przy tym tożsamości. We wspomnianych tekstach podmiot jawi się jako „dwór” lub „dom”. Jest to podmiot zbiorowy obejmujący sobą nie tylko mężczyznę/głowę/ojca, ale również pozostałych domowników, do których należy zaliczyć kobietę/doradcę/matkę, służących oraz dzieci. Ukształtowana długo przed XVI w. tradycja została utrwalona w utworze Domoustrój autorstwa protopopa Sylwestra (Kolesov i Rozhdestvenskaya, red., 2007), ojca duchowego Iwana IV [Groźnego]. W tym dziele w sposób wyraźny utrwalono ustrój życia średniowiecznego człowieka. Cały układ domowy został wbudowany w świecką przestrzeń, ale zarazem w sposób organiczny jest obecny w duchowym wymiarze. W Domoustroju życie rodzinne jest rozumiane jako ścisłe przestrzeganie przez każdego domownika wyznaczonej funkcji, „służenia” domowego, świeckiego i duchowego. Te „służenia” znajdują odzwierciedlenie w samej strukturze omawianego tekstu. Na początku w Domoustroju jest mowa o życiu duchowym jako „duchowym budownictwie” oraz reglamentacjach z nim związanych (rozdziały 1-14), dalsze ustępy są poświęcone „świeckiemu budownictwu” (rozdziały 15-18), wreszcie trzeci obszerny dział zwiera wskazówki dotyczące „domowego budownictwa” (rozdziały 19-63).

Człowiek przeżywa życie niejako naraz, w trzech wymiarach ułożonych w hierarchiczną, paternalistyczną strukturę, która zabezpiecza jedność życia narodu, jedność tradycji i obrządków, ściśle utrwalonych w Domoustroju, nadając całościowość bytowaniu, kształtując przestrzeń zbiorowej (rodowej, rodzinnej, cerkiewnej) tożsamości. Można przypuszczać, że właśnie w okresie narodzin ideologii moskiewskiej państwowości dochodzi do stanowienia szczególnego rodzaju historycznych form tożsamości: wyznaniowej - wiążącej się z układem duchowym, 
podległościowej - kojarzonej ze świeckim układem oraz rodowej/rodzinnej-związanej z domem.

W zgodności ze średniowiecznymi wyobrażeniami Domoustrój w postaci gotowej przedstawia hierarchię podstawowych organizujących form: państwo - cerkiew - rodzina, wraz z wiodącą dla tej hierarchii zasadą pojednania na podstawie woli, rozumianej jako dobro wspólne (Kolesov i Rozhdestvenskaya, red., 2007, s. 312).

Głównym zadaniem pana/gospodarza domu jest „urządzenie domu”, wychowanie powierzonych jego opiece domowników. W ramach „urządzenia domu" role społeczne oraz sensy życiowe też zostają wyraźnie wyartykułowane. W Domoustroju, jak podkreślają badacze, po raz pierwszy pojawiają się takie określenia jak „mężczyzna” oraz „kobieta” (odpowiednio - służenie męża oraz służenie żony), którym odpowiadają pewne modele zachowania, praktyki oraz role społeczne.

Poprzez wprowadzenie nowych słów ten reglamentujący XVI-wieczny tekst oddzielał od siebie pole znaczeniowe wcześniej używanych zamiennie synkretycznych terminów. Mąż - zgodnie z wcześniejszymi wyobrażeniami - to zarazem człowiek, mężczyzna oraz małżonek, podobnie jak i żona - to gospodyni, kobieta i małżonka... Podział pojęć podkreśla się za pomocą różnych słów: mąż - mężczyzna, żona, żonka - kobieta; stopniowo te słowa stawały się znakami odmiennych społecznych cech człowieka (Kolesov i Rozhdestvenskaya, red., 2007, s. 335).

Dla nosicieli kultury to, o czym pisze Sylwester, było rzeczą oczywistą i niewątpliwą, ale właśnie ujęcie tego w tekście czyni to bardziej wymownym, zarazem pozwalając popatrzeć na opisywany przedmiot niejako $\mathrm{z}$ innej strony, uświadomić go sobie i uczynić przedmiotem racjonalnej percepcji, a zrazem poddać krytycznemu odbiorowi, w tym też i możliwemu odrzuceniu.

W okresie panowania Iwana Groźnego kształtuje się właściwie cały korpus tekstów opisujących model identyczności w rosyjskim państwie jedynowładczym, niejako podsumowujących tradycję - jest to Wielkie Menologium - zbiór ksiag, „które w ziemi ruskiej są pozyskiwane”, Dostojna ksiega carskiego rodowodu - historyczny obraz pojednania wszystkich ziem ruskich w jedyne państwo, Ksiega stu rozdziatów - ustawodawczy zbiór, reglamentujący i porządkujący życie religijne społeczeństwa rosyjskiego, wreszcie Domoustrój - wykładnia idealnego modelu ułożenia życia codziennego człowieka, jego domu i świata. Status kobiety na danym etapie historycznym, jej role społeczne, można zrekonstruować na podstawie dokumentów prawnych z epoki, zaś jej obraz - na podstawie 
tekstów hagiograficznych i literatury pięknej. Jak jednak zauważa Dymitr Lichachow, „staroruscy pisarze rzadko kierowali spojrzenie na córki, żony i matki swoich bohaterów” (Lichachov, 1987, s. 70). Przy tym badania, w których jest poddany analizie charakter i obraz kobiety w dawnym rosyjskim piśmiennictwie, nie są liczne. Wśród nich warto wymienić przedrewolucyjne wydania - prace Fiodora Buslajeva (Buslajev, 1990), Vladimira Ikonnikova (Ikonnikov, 1874); badania autorów współczesnych - historyków, filozofów, literaturoznawców: Natalii Pushkarevej (Pushkareva, 1989; 1996), Ludmily Solonenko (Solonenko, 2006), Piotra Snesarevsky'ego (Snesarevsky, 1983), Tatiany Chumakovej (Chumakova, 2004) $\mathrm{i}$ innych.

W niniejszym opracowaniu będzie nas interesował przede wszystkim dom jako forma myślenia o podmiocie.

Gdy Iwan Groźny uśmiercał wraz z bojarzynem, który stracił zaufanie cara, nie tylko rodzinę, ale też wszystkich jego służących, wynikało to nie z domniemanego strachu przed zemstą (jak gdyby chłop z prowincji mógł stanowić niebezpieczeństwo dla cara!), ale z wyobrażenia o tym, że z punktu widzenia prawa wszyscy ci ludzie stanowili wspólną osobę wraz z głową domu i, odpowiednio, kara miała dotyczyć też ich (...). To samo pojęcie zbiorowej (w danym przypadku - rodowej), nie zaś indywidualnej osoby, leży np. u podstaw krwawej zemsty, gdy to cały ród zabójcy był postrzegany jako ponoszący prawną odpowiedzialność. Siergiej Sołowiow [historyk] w sposób przekonujący kojarzył ówczesny system przydzielania wyższych stanowisk państwowych [polegał on na obsadzaniu stanowisk według starszeństwa rodowodu kandydatów oraz stanowisk zajmowanych przez ich przodków - tłum.] z wyobrażeniami o zbiorowej rodowej osobie: „Jest rzeczą zrozumiałą, iż przy takiej ścisłej więzi sojuszu rodowego, przy takiej odpowiedzialności wszystkich członków rodu jeden za drugiego, znaczenie poszczególnej osoby w sposób nieunikniony zanikało wobec znaczenia rodu; jedna osoba była nie do pomyślenia bez rodu: znany Iwan Petrow nie był do pomyślenia jako jeden Iwan Petrow, był natomiast postrzegany zawsze jako Iwan Petrow wraz z braćmi oraz bratankami. Przy takim utożsamieniu osoby z rodem, awans służbowy jednej osoby oznaczał awans całego rodu, degradacja służbowa jednego członka rodu - degradację całego rodu" (Lotman, 1992, s. 14-15).

Dom występuje tu jako konkretny przypadek rodu, ale nie sprowadza się on jedynie do rodziny powiązanej więzami krwi, z punktu widzenia prawa obejmował też służących, nieruchomości oraz bydło. Zarazem, taki 
dom był personifikowany w postaci głowy rodziny. Problem odpowiedzialności świadczy o tym fenomenie jako prawnym i/lub etycznym. Odpowiedzialność prawna nie jest delegowana, lecz koncentruje się w personifikowanym domu (głowie rodziny) i to właśnie on występuje jako instancja władzy i odpowiedzialności dla domowników, odpowiednio, jego zadaniem jest karać za występki. Możemy dostrzec podobny schemat pionowego rozłożenia władzy w politycznej organizacji społeczeństwa średniowiecznego, w tym też - na Rusi. W kulturze tradycyjnej kanały dystrybucji władzy i odpowiedzialności są faktycznie zbieżne, obszar prawa pokrywa się z obszarem politycznym (system sądownictwa jest budowany wokół postaci wielkiego księcia lub cara). W podobny sposób jest też urządzona struktura domu.

W Domoustroju ogólny układ domu jest przedstawiony jako triada ojciec - matka - dzieci/służący. Podobna struktura wyczerpuje sobą cały zbiór działających i odpowiedzialnych podmiotów domu. Świat mężczyzny zakłada obecność w trzech strukturach - domowej, świeckiej oraz duchowej, w których pełnił on ściśle zarezerwowane dla niego funkcje w systemie paternalistycznym, ponosząc odpowiedzialność wobec świata i Boga za układ, porządek w domu/rodzie/rodzinie, porządek nie tylko gospodarczy, ale przede wszystkim duchowy i moralny. Ojciec (głowa rodziny) jest przedstawicielem domu poza nim, on ponosi odpowiedzialność za wszystko, co może się wydarzyć w domu oraz poza nim z udziałem domowników. Co by się nie stało, odpowiedzialność w obliczu Boga i cara musi ponosić właśnie on.

Jeśli mąż sam tego nie czyni, co w tej księdze napisano, i żony nie poucza, i służących swych, i dom swój prowadzi nie po bożemu, i o duszę swoją się nie troszczy, i ludzi swoich zasad podobnych nie naucza - sam siebie zgubi w tym życiu i następnym oraz dom swój i wszystkich pozostałych ze sobą. Gdy zaś mąż dobry dba o własne zbawienie i żonę, i dzieci własne poucza, również jak i służących własnych, wszelkiego strachu Bożego poucza i godnego życia chrześcijańskiego, zgodnie z tym, co tu zostało napisane, wówczas on wraz ze wszystkimi w łasce i po bożemu życie swoje przeżyje i łaski Bożej dostąpi (Kolesov i Rozhdestvenskaya, red., 2007, s. 166).

Świat kobiety - to przede wszystkim dom (za który ona odpowiada przed mężem) i świat duchowy (przy tym, że w Cerkwi, wobec ojca duchowego, wobec Boga mężczyzna ponosi odpowiedzialność za dom i wszystkich domowników), kobieta jest strażniczką domowego układu (zarówno od strony gospodarczej, jak też - wyznaniowej). Świat kobiety był wyraźnie wyznaczony, określony, jej głos nie był słyszalny, jednak mówienie 
o „milczeniu” kobiety tej epoki (wykorzystując termin Gustawa Szpeta) jest pewnym uproszczeniem.

Matka (żona głowy rodziny) jest doradcą ojca, jego pomocnikiem, na niej spoczywa troska o całe gospodarstwo. Jej odpowiedzialność ogranicza się jednak do tego, co jest wewnątrz domu (gospodarstwo). W danym przypadku określenie matki jako prawej ręki jest nie tylko metaforą, ale też wskazaniem na nierozerwalną jedność w tym tożsamościowym modelu matki z ojcem (mąż i żona to jedno). Nawet obraz złej żony, aspirującej do dominowania w rodzinie, opisany przez Daniela Zatoczonego (Slovo..., 1932), nie jest niezgodny z modelem przedstawionym w Domoustroju. Opisując bowiem nieodpowiedniość ideału normatywnego z rzeczywistą praktyką, Daniel nie znosi, ale raczej utwierdza go. Daniel nie postrzega kobiety inaczej niż w roli żony, to znaczy poza rodziną (Romanow, 2002, s. 256). Dyskurs żeński w rosyjskim średniowieczu - to dyskurs żony męża.

Ostatnim ogniwem przedstawionej wyżej triady są służący i dzieci, którzy pod względem funkcjonalnym nie są przez autora Domoustroju od siebie oddzieleni. Żyć sprawiedliwie oznacza bowiem żyć, „żonę pouczając”, ale też utrzymywać „domowników swoich nie poprzez zniewolenie, nie za pomocą bicia, nie poprzez ciężką pracę, ale podobnie do dzieci, które zawsze są w spokoju, ubrane i najedzone, w ciepłym domu i zawsze są w porządku” (Kolesov i Rozhdestvenskaya, red., 2007, s. 138). Przedstawione w Domoustroju funkcjonalne pojednanie domowników [nienależących do rodziny - tłum.] z dziećmi odpowiada postawie kulturowej, zgodnie z którą dzieci, podobnie jak domownicy, znajdują się na najniższym stopniu intelektualnego rozwoju. Właściwie już samo słowo „domownicy”, które pierwotnie było synonimem „czeladzi”, oznaczając wszystkich, którzy pod strzechą domu zamieszkują, ukształtowało się jako połączenie dwóch słów - „domowe” oraz „czeladź”. Stopniowe semantyczne oddzielanie i zarezerwowanie dla służących określenia „czeladź” oraz mniej oczywistego określenia jako „domowników” niespokrewnionych członków rodziny stało się językowym wyrazem nowej dystrybucji funkcji kulturowych oraz stratyfikacji społecznej. Pod względem etymologicznym oraz syntaktycznym określenia „domownicy” [domochadtsy] oraz „dzieci” [chada] są natomiast ze sobą zbieżne, o czym też świadczy Domoustrój, gdzie zostały one ujęte w jedną grupę. Tego rodzaju pojednanie nie jest bynajmniej sprawą przypadku. Wspomnieliśmy już o czynniku odpowiedzialności, który wyznacza podział funkcji oraz miejsce w hierarchii domowników, chociaż słowa „hierarchia” używamy tu jako przenośni. 
Odpowiednio do średniowiecznego kulturowego modelu świadomości powszedniej, ten, któremu bliżej do Boga, jest pod każdym względem lepszy (mądrzejszy, piękniejszy, uczciwszy, odważniejszy itd.), stąd też domniemanie posiadania wszystkich tych jakości przez wszystkich przedstawicieli arystokracji (oni są bliżej Boga) oraz odmowa możliwości posiadania takich cech przez przedstawicieli niższych warstw społecznych. $Z$ tego też wynika traktowanie ich ze strony arystokracji jak dzieci, co w pełni odzwierciedla model domu (rodziny) wraz z odpowiednim podziałem obowiązków, funkcji oraz wymagań. Ponieważ ojciec jest bliżej Boga i przed nim odpowiada, to właśnie ojciec jest postrzegany jako nosiciel rozumu, co pozwala mu „pouczać” (wychowywać) dzieci oraz resztę domowników.

(...) bliskie powiązania wewnątrz rodu powściągały młodzieńców, którzy, będąc wychowywani w doskonałym poważaniu i niekwestionowanym posłuszeństwie wobec rodziców, zobowiązani byli szanować wszystkich starszych w swoim rodzie, właśnie w nich mając srogich stróży własnych uczynków oraz obrońców w każdej potrzebie (Shcherbatov, 1858, s. 32).

Ojciec poucza matkę, która zarazem odgrywa rolę doradczyni. Sylwester zaleca „codziennie i co wieczór, po spełnieniu obowiązków duchowych, ale też nad ranem, obudziwszy się na dźwięk dzwonu oraz po modlitwie, mężowi z żoną radzić się w sprawach gospodarczych" (Kolesov i Rozhdestvenskaya, red., 2007, s. 154). Dzieci oraz służący, znajdujący się na samym dole rodzinnej „hierarchii”, są oddaleni od Boga, ale zarazem ponoszą minimalną odpowiedzialność, i w tym sensie między dziećmi a służącymi brak funkcjonalnej różnicy. Ponoszą odpowiedzialność wobec ojca i matki, należy ich pouczać, wychowywać. „Kochać i chronić ich, ale też i przez strach ratować, karząc i pouczając, a nawet, po rozeznaniu sytuacji, też pobić. Karz dzieci w młodości - ucieszą cię w starości twojej" (Kolesov i Rozhdestvenskaya, red., 2007, s. 228). Formy wychowania matki oraz dzieci/służących istotnie różnią się od siebie. Sylwester zaleca traktować żonę „z miłością i wzorcowym nastawieniem” (Kolesov i Rozheddestvenskaya, red., 2007, s. 261) i tylko w wyjątkowych sytuacjach pouczać żonę za pomocą fizycznej perswazji. Zarazem, dla dzieci oraz sług oddziaływanie fizyczne stanowi najbardziej efektywny sposób uprzytomnienia.

Karz syna swojego w młodości jego, wówczas ucieszy on ciebie w starości twojej, nadając duszy twojej piękna. Niech nie będzie ci żal młodego w trakcie jego bicia: jeśli prętem ukarzesz go, nie zginie, lecz zdrowszy będzie, bowiem ty, umartwiając jego ciało, zbawiasz jego duszę od śmierci. 
Jeśli masz córkę, na nią też skieruj swoją srogość, w ten sposób zachowasz ją od nieszczęść cielesnych (...). Kochając syna swojego, powielaj jego rany, a nie ustaniesz później z niego się cieszyć. Karz syna swojego od wieku młodzieńczego, a ucieszysz się z niego w dojrzałości jego, wśród nieżyczliwych tobie będziesz mógł nim się pochwalić, tak iż pozazdroszczą tobie wrogowie twoi. Wychowuj dzieci poprzez zakazy i odnajdziesz w nich spokój i błogosławieństwo. Bez powodu się nie śmiej, bawiąc się z nimi: $w$ małym popuścisz - w wielkim ucierpisz w smutku, w przyszłości niejako drzazgi wsadzisz we własną duszę. Otóż nie popuszczaj mu w młodości, ale policz mu żebra, zanim on wyrośnie, wówczas, stając się mężem, nie zawini wobec ciebie i nie przysporzy tobie smutku i cierpienia duszy, nie doprowadzi domu do upadku, do roztrwonienia majątku, nie da powodów do wyrzutów ze strony sąsiadów, do naśmiewania się przez wrogów, do obwiniania przez władzę czy do złego twego żalu (Kolesov i Rozhdestvenskaya, red., 2007, s. 159).

Przyczyn podobnego traktowania kar cielesnych należy szukać w chrześcijańskim przeciwstawianiu tego, co duchowe, temu, co cielesne, polaryzacji duszy i ciała. Aby zbawić duszę, należy umartwiać ciało, uśmierzać wolę, jeśli zaś tego się nie uczyni, wówczas ciało doprowadzi do śmierci duszy (zaciagnie ją do piekła). Dlatego właśnie wychowanie jest postrzegane jako praktyka wybudowania duszy.

Zatem [w czasach powstania Domoustroju - tłum.] wiekowa i płciowa tożsamość sprowadzała się do wyobrażenia o własnym miejscu w hierarchii rodzinnej, w domu, jako wewnątrz pewnej całości.

Powyższy model jest odtwarzany np. w dziełach Andrieja Kurbskiego, gdy opisuje on własną teorię mądrych doradców. Mimo dość postępowych poglądów, oświeceniowego traktowania wiedzy, jego wyobrażenia o państwie odtwarzają model przedstawiony w Domoustroju. Odpowiednio do nich, na państwo się składają, podobnie jak na rodzinę, trzy części - car, mądrzy doradcy oraz naród.

Wybudowany przez Iwana Groźnego, za aktywnego udziału Kurbskiego, system państwowych pomocników, opisywany też jako „teoria mądrych doradców”, może być porównany do modelu rodziny przedstawionego wyżej: ojciec - matka (doradca) - dzieci/służący. Pod każdym względem wszystkie składniki struktury, opisanej przez Kurbskiego, odpowiadają trzem składnikom wymienianym w Domoustroju. Zdaniem Kurbskiego, podobny model został realizowany już we wczesnym okresie panowania Iwana IV. 
Car, podobnie do ojca, jest odpowiedzialny wobec Boga, ale odpowiedzialność ta poszerza się na wszystko, co się dzieje w państwie. Doradcy, których Kurbski określa w Powieści o państwie Moskiewskim jako „radę wybraną”, funkcjonalnie odpowiadają matce w Domoustroju. Konieczność istnienia tej warstwy (funkcji) Kurbski tłumaczy niedoskonałością człowieka. Car - jako człowiek - może się pomylić, dlatego jest potrzebny ktoś, kto będzie mógł pomóc mu w podjęciu odpowiedniej decyzji. Taka decyzja już z założenia będzie właściwa dlatego, że rada składa się z arystokratów, którzy, zgodnie ze średniowiecznymi wyobrażeniami, są bliżej Boga, odpowiednio - są mądrzejsi, piękniejsi, odważniejsi, uczciwsi itd. [aniżeli niższe warstwy społeczne - tłum.]. Podobnych ludzi Kurbski określa jako „silnych w Izraelu” (Lurie i Rykov, red., 1993, s. 119). Wreszcie, naród jako obiekt opisywania jego funkcji Kurbskiego wcale nie interesuje.

Iwan IV, z kolei, proponuje inną wersję ogólnej struktury społecznej, która ma obejmować tylko dwa człony - cara oraz poddanych. Struktura taka znalazła swój wyraz w lakonicznej formule: „obdarzać własnych poddanych zawsze nam było wolno, wolno też nam było ich uśmiercać” (Kolesov i Rozhdestvenskaya, red., 2007, s. 136). Zarazem, Iwan Groźny występuje z krytyką teorii mądrych doradców:

O narodach bezbożnych co już mówić! Przecież tam u nich carowie nie panują nad swoimi królestwami, jak im polecą ich poddani, tak też rządzą. Natomiast rosyjscy samodzierżcy od początku sami panują nad własnym państwem, nie zaś bojarowie wraz z możnowładcami (Kolesov i Rozhdestvenskaya, red., 2007, s. 126).

Cerkiewno-polityczny schemat XIII w., wyrażony w Stowie Daniela Zatoczonego za pomocą formuły „żonom głową są mężowie, zaś mężom książęta, zaś książętom - Bóg” (Slovo..., 1932, s. 59), odzwierciedlający tradycyjne wyobrażenia i wskazujący na źródła oraz instancję władzy i odpowiedzialności, w żaden sposób w koncepcji Iwana Groźnego nie jest zaburzony, car po prostu usuwa z niego jeden „zbędny” element.

Rzekł prorok: biada domu, gdy rządzi w nim żona; biada miastu, jeśli wielu w nim rządzi. W carstwie rządy wielu są podobne do kobiecego szaleństwa: jako że żona nie jest w stanie opanować i poustawiać własne zachcianki, raz tak, raz owak, tak też w carstwie panowanie wielu; i mocni są, i mądrzy, ale jeden w taki sposób, inny zaś - w inny (Lurie i Rykov, red., 1993, s. 57).

Za sprawą odrzucania środkowego ogniwa powyższej trójdzielnej struktury stała się ona strukturą bipolarną. Do czego są potrzebni doradcy, skoro troszczą się oni jedynie o własny interes, skoro są podatni 
na korupcję, podczas gdy całą odpowiedzialność nadal ponosi car? W ten sposób car odrzuca domniemanie na temat wyróżniających cech posiadanych przez przedstawicieli arystokracji, przesuwając akcent na rzeczywisty stan rzeczy.

Ponieważ „Bóg daje władzę temu, komu chce” (Lurie i Rykov, red., 1993, s. 167), patrząc na skuteczność rządzącego, można wnioskować o tym, po czyjej stronie jest Bóg i czyje uczynki akceptuje. Powodem powstania drugiego listu Iwana Groźnego, w trzynaście lat po pierwszym, stały się zwycięstwa militarne armii rosyjskiej w wojnie inflanckiej, w szczególności zdobycie miasta Wolmar (rezydencji Kurbskiego, skąd rozpoczęto korespondencję). Car mówi o Bożym poparciu dla siebie i co za tym idzie - o słuszności własnych decyzji i działań. Daje mu to powód do złośliwych uwag pod adresem Kurbskiego: „Tam, gdzie ty zamierzałeś od wszelakich swoich prac odpocząć, do Wolmaru, do miejsc twojego wyciszenia przeprowadził nas Bóg: dopadliśmy ciebie i jeszcze dalej powędrować konno musiałeś” (Lurie i Rykov, red., 1993, s. 167).

W ten sposób powstaje nowy, tym razem binarny model, który jest przekładany zarówno na rodzinę, jak i na dom. Staje się on podstawą odpowiedniego pionowego systemu, w którym założono przeciwstawienie męża pozostałym domownikom. Miało to doprowadzić do upadku podmiotu zbiorowego i pojawienia się genderowej tożsamości już za czasów cara Piotra Wielkiego. Wówczas kształtuje się też nowy typ myślenia, w dużej mierze przypominający „myślenie wolnorynkowe”, którego podstawą miało się stać zaakceptowanie wolnej konkurencji pomiędzy podmiotami.

Obraz kobiety jako części rodziny, elementu zbiorowego podmiotu, jako żony, nie jest burzony także w nielicznej literaturze hagiograficznej, której główną bohaterką była kobieta. Obyczajowy i etyczny wzorzec reprezentowany przez święte kobiety raczej nie może być postrzegany jako wzorzec samodzielny. Podejście cerkiewne, deklarujące równość wobec Boga, i co za tym idzie - nietolerujące, przynajmniej formalnie, żadnych rozróżnień, w tym też - genderowych i płciowych, z jednej strony, oraz praktyka zakonna, nakładana na ustrój patriarchalny kultury tradycyjnej, z drugiej strony, nie sprzyjały wyłonieniu dyskursu żeńskiego, wolnego od dominacji dyskursu zarówno rodzinnego, jak i cerkiewnego.

Iwan Groźny wprowadza praktykę zasłużonych (nie zaś przyznawanych na mocy szlachetnego urodzenia) przywilejów, które były hojnie nadawane arystokratom. Podobne zmiany miały doprowadzić do destabilizacji 
tradycyjnej stratyfikacji społecznej. Cerkiewny kryzys XVII w. spowodowany reformą liturgiczną wyraźnie ujawnił obecność konfliktu pomiędzy stratyfikacją cerkiewną i ,rodzinną”. Na początku XVII w. wzrasta samodzielność kobiet w sprawach duchowych, np. w kwestii wyboru wiary. Wystarczy przywołać słynne staroobrzędowe obrazy bojarzyni Teodozji Morozowej oraz [jej siostry - tłum.] księżnej Eudokii Ursusowej. Mimo tradycjonalistycznej postawy staroobrzędowców to właśnie ich zwolenniczki (przynajmniej znane liderki tego ruchu) faktycznie burzą system hierarchii, przejmują bowiem czysto męskie funkcje. Kobiety te ponoszą bezpośrednią odpowiedzialność wobec państwa; występują w roli zewnętrznych przedstawicieli zbiorowego podmiotu, którym jest w danym przypadku ruch staroobrzędowców jako całość; wchodzą w otwartą opozycję wobec „zła”, co jest właściwe dla bohatera, świętego wojownika, rycerza, na skutek czego stają się przedmiotem heroizacji. Dokonane przesunięcie granic pomiędzy stratami pozwoliło np. na legitymizację politycznego wywyższenia księżnej Sofii, stało się też podstawą sformatowania od nowa całej kulturowej i społecznej mapy strat, dokonanego w ramach reform Piotra I. Skutkiem tego było, z kolei, wykształcenie samodzielnego żeńskiego dyskursu. Właśnie epoka Piotra Wielkiego i następujący po niej długi okres „rządów kobiecych” w sposób radykalny odmienia społeczną pozycję kobiety.

Za czasów panowania Piotra Wielkiego kształtuje się nowożytny, indywidualistyczny model tożsamości: „każdy sam za siebie”, zaś podmiot zbiorowy się rozsypuje. W sytuacji zaniku tożsamości zbiorowych wzrasta potrzeba dystansowania się od innych grup społecznych. Kodeks etykiety zawierający wskazówki dla młodzieży z czasów Piotra Wielkiego zatytułowany Młodzieńczej uczciwości lustro radzi przedstawicielom wyższych sfer

(...) zawsze pomiędzy sobą rozmawiać w językach obcych, aby do nich się przyzwyczaić móc, a zwłaszcza [wówczas], gdy mówić coś tajnego przyjdzie, tak aby służące i pokojówki dowiedzieć się [o treści rozmowy] nie mogli, ponadto zaś - aby można było ich rozpoznać pośród aroganckich głupców (Alferov i Gruzinsky, 1907, s. 10).

Rodzi się też potrzeba płciowej identyfikacji, odróżnienie siebie od innego jako przedstawiciela odmiennej płci. Przy tym postrzeganie kobiety przez mężczyzn staje się bardziej negatywne aniżeli było przed tym. 
Książę M.M. Szczerbatow jako pierwszy zauważył i opisał tę tendencję w swoim pamflecie $O$ zepsuciu obyczajów w Rosji. Jako tradycjonalista i konserwatysta występuje z krytyką europeizacji państwa, dostrzegając w niej przyczyny upadku obyczajowego. Jego krytyka dotyczy jednak nie tyle Piotra I, który sam był pozbawiony pragnienia komfortu i luksusu, ile zaprowadzonych przez niego przemian społecznych i zburzenia tradycyjnej tożsamości rodowej. W sytuacji, gdy każdy człowiek dba wyłącznie o własny interes, pojawia się wolna konkurencja, w której zwyciężyć, zdaniem Szczerbatowa, można jedynie, posiadając środki do tego, aby być zauważalnym. Brak odpowiedzialności za cały ród znosi etyczne ograniczenia, zaś głównym celem wszelkich starań staje się zdobycie środków do zwycięstwa w konkurencyjnym wyścigu.

(...) teraz już nie ród [pochodzenie], ale stopnie [społeczne], rangi, zasługi i wysługi; i tak każdy zaczął ubiegać się o stopnie, a przecież nie każdy potrafi poczynić rzeczywiste zasługi, wobec czego, w obliczu braku [prawdziwych], zaczęli [wszyscy] starać się przypodobać, na wszelki sposób pochlebiając i zdobywając przychylność władców i panów wielmożnych (Shcherbatov, 1858, s. 45).

Wskutek tego zaczęło się szerzyć przechwalanie się i rywalizacja w luksusie, stąd też kradzieże, potakiwania i korupcja.

Zmiany zachodzą również w ułożeniu życia rodzinnego oraz w relacjach pomiędzy płciami. Szczerbatow postrzega kobietę jako podmiot odpowiedzialności na równi z mężczyznami, a ponieważ „płeć żeńska jest zazwyczaj bardziej skłonna ku luksusowi aniżeli płeć męska” (Shcherbatov, 1858, s. 49), toteż winę ponosi większą.

Doszło do przemiany Rosjan z brodatych na wygolonych, z długich brzegów [odzieży] na krótkie, stali się oni bardziej bezpośredni w komunikacji, czyniąc przy tym rzeczy haniebne i niegodne dobrych obyczajów (Shcherbatov, 1858, s. 48).

Przykładem tego mogą być zebrania i bale, na których kobiety i mężczyźni starali się przypodobać płci przeciwnej; najpierw kobiety dostrzegły, iż mężczyźni bez brody są całkiem atrakcyjni, a następnie także mężczyźni zauważyli atrakcyjność upiększających się kobiet. Podobne dążenia jeszcze bardziej wzmacniają zepsucie obyczajów, zwiększają szkody moralne, co, jak uważa Szczerbatow, jest wyraźną tendencją przez cały XVIII w. Za czas najgłębszego upadku moralnego uważa on okres panowania Katarzyny II, bowiem 
jej moralność opiera się na podstawach nowych filozofów, to znaczy nie jest ona oparta na twardym kamieniu prawa Bożego, a zatem, jako że w chwiejnych świeckich priorytetach zakorzeniona, wraz z nimi narażona jest na chwiejność (Shcherbatov, 1858, s. 97).

Jednym z wyznaczników epoki staje się udział kobiet w społeczno-politycznym życiu Rosji, pojawienie się prozy kobiecej, przede wszystkim autonarracji kobiecej, co nie było typowe dla poprzednich epok. To właśnie w XVIII w. usłyszano głos kobiety, kobiecą historię w formie zapisek lub notatek. Kobiety zaczęły otrzymywać świeckie wykształcenie, którego posiadanie pozwalało na skuteczne konkurowanie z mężczyznami w wybranych obszarach. Przy tym trzeba zaznaczyć, że kobieta epoki oświecenia reprezentowała sobą rzadkie pojednanie tradycji oraz novum w sferze moralności i kultury, co pozwala w szczególny sposób spojrzeć na kształtowanie się dyskursu płci XVIII w.

Jednocześnie $\mathrm{z}$ oczywistym priorytetem racjonalistycznego pierwiastka w kulturze oświecenia zachowano też ciąłość z poprzednią średniowieczną tradycją upatrującą fundamenty moralności w dążeniach duszy i serca. Dążąc do podołania jednej ze sprzeczności teorii oświeceniowych pomiędzy rozumem a uczuciami, rosyjscy pisarze i myśliciele zwracają się ku kategorii „duszy”, dostrzegając w niej syntezę, punkt spotkania racjonalnego i zmysłowego pierwiastka w człowieku. W kontekście teorii oświeceniowych kobieta jawi się przede wszystkim jako nosicielka zmysłowej, naturalnej, a więc - moralnej zasady. Dusza i serce (jako centrum tejże duszy) są podstawą moralnej zasady w człowieku, która posiada zarówno rozumowe, jak i zmysłowe uzasadnienie. Idea moralności w oświeceniu rosyjskim jest uzasadniana zarówno racjonalistycznie, jak też za pomocą „serdecznych” argumentów i podstaw, co pozwala świadomości oświeceniowej zachować ideę integralnego podmiotu moralnego, ideę, która w dużej mierze określi swoistość i specyfikę kobiecych obrazów w rosyjskiej literaturze pięknej, w kulturowej, moralnej oraz religijnej tradycji. To właśnie kobieta ze swą zdolnością do poznania sercem, moralną intuicją i wrażliwością będzie postrzegana przez świadomość oświeceniową oraz całą późniejszą tradycję myśli i literatury rosyjskiej jako nosicielka naturalnej i moralnej zasady, jako osobowość całościowa.

Kobieta epoki oświecenia to przede wszystkim wykształcona, zaangażowana w czytanie książek rosyjska arystokratka (mówimy przede wszystkim o arystokracji, bowiem wartości oświeceniowe przemawiały głównie do wykształconej części rosyjskiego społeczeństwa, w stopniu znikomym znajdując oddźwięk w pozostałych warstwach społecznych). Efektem procesów sekularyzacji właściwych dla epoki oświecenia stało się to, że już od połowy XVIII w. prawosławie przestało kształtować światopogląd rosyjskiej 
arystokracji, dochodzi do „sekularyzacji” świadomości i kultury, główną rolę $w$ duchowym i moralnym wychowaniu przyjmuje literatura i filozofia.

Już pod koniec XVII w. i na początku XVIII w., pod wpływem procesów sekularyzacji i nasilającego się wpływu kultury zachodnioeuropejskiej, zmienia się charakter literatury, przede wszystkim moralistycznej, która wyznaczała stereotypy zachowania i określała specyfikę norm i przepisów moralnych. W tym okresie wzrasta zainteresowanie wobec zewnętrznych form zachowania, etykiety, o czym można sądzić na podstawie lektury licznych literackich tłumaczeń tego okresu. Wraz z rozwojem świeckiej, sekularyzowanej kultury w XVIII w. literaturze coraz częściej przydziela się wychowawczą, „nauczycielską" funkcję. To literatura, w swojej różnorodności gatunkowej, wychowuje rosyjską arystokratkę. $\mathrm{W}$ poezji, dramacie, pismach historycznych odnajduje ona pokarm dla umysłu i przykłady do naśladowania. Dlatego właśnie ówczesna literatura może służyć za główne źródło rekonstrukcji świadomości etycznej, norm i wartości moralnych rosyjskiej kobiety epoki oświecenia. Literatura moralizatorska wpaja te niezbędne, trwałe stereotypy, które konstytuują sferę duchową i emocjonalną warstwę osoby, tworzą całościowe spojrzenie na świat oraz miejsce i cel człowieka w tym świecie.

Rosjanka epoki oświecenia jest nie tylko wykształconą, spędzającą czas na czytaniu książek arystokratką. Według świadectwa rosyjskiego historyka V.S. Ikonnikowa, w drugiej połowie XVIII w. około 70 kobiet zajmowało się w Rosji pisarstwem (Ikonnikov, 1897, s. 65). Wiek XVIII pozostawił dla kultury rosyjskiej rzadkie dokumenty - wspomnienia, notatki, swoiste wyznania kobiet oświeceniowych, w tym zapiski Katarzyny II, księżnej Daszkowej, Odręczne notatki księżnej Natalii Dotgorukowej (Dolgorukaya, 1913) oraz rozległe dziedzictwo epistolarne, które jeszcze tylko czeka na przebadanie i włączenie w kontekst ówczesnej kultury, co będzie służyć przybliżeniu tradycji oraz zrekonstruowaniu obrazu kobiety epoki rosyjskiego oświecenia.

Epoka panowania kobiet (XVIII w.), która w naturalny sposób zbiegła się z okresem rosyjskiego oświecenia, stała się czasem utrwalania niezależnego dyskursu kobiecego - już nie w ramach dyskursów rodzinnego czy kościelnego - wolnego od jakichkolwiek zbiorowych tożsamości poza jednorodną genderową tożsamością.

Dyskurs genderowy nie wykształcił się od razu. W przestrzennym wyobrażeniu o podmiocie, w którym najważniejszy okazuje się podział funkcji odpowiednio do wiekowych i płciowych charakterystyk, dyskurs 
genderowy był nieobecny. Osoby starsze i dzieci są tu faktycznie pozbawione tożsamości genderowej, zaś ich obowiązki i prawa wiążą się bezpośrednio z pełnionymi w rodzinie funkcjami, które wyraźnie się różniły od funkcji męża czy żony. Śmierć jednego z małżonków oznaczała, że drugi z nich przejmował wszystkie funkcje początkowo wyznaczone dla obojga. W ten sposób dochodzi do automatycznego przeformatowania przynależności do męskiej lub żeńskiej warstwy. Należy w tym przypadku mówić o odrębnej, hybrydowej warstwie wdowca/wdowy, w której cechy płci wciąż są obecne, ale raczej jako pozostałości po uprzednio pełnionej funkcji.

Okolicznością umożliwiającą powstanie dyskursu genderowego stało się zniesienie podmiotu zbiorowego (dom, państwo) za czasów Iwana Groźnego. Wówczas, mimo dalszego istnienia systemu przedstawionego w Domoustroju, równolegle z nim kształtowała się forma podziału odpowiedzialności i nowego podziału funkcji pomiędzy jednostkami. Ostatecznie dyskurs genderowy ukształtował się w XVIII w. w wyniku swobodnej konkurencji między podmiotami. Tożsamość genderowa stała się integralnym składnikiem praktyki kulturowej, weszła do praktyki kulturowej, tworząc zarazem podstawy samodzielnych męskich i żeńskich dyskursów.

\section{Bibliografia}

Alferov, A.D. i Gruzinskij, A.E. (1907). Russkaya literatura XVIII veka. Khrestomatiya [The Russian literature of the XVIII century. Reader]. Moscow: Shkola.

Buslaev, F.I. (1990). Ideal'ny'e zhenskie kharaktery' Drevnej Rusi [Ideal female characters of Ancient Russia]. W: F.I. Buslaev, O literature. Issledovaniya. Stat'i [On Literature. Researches. Articles]. Moscow: Khudozhestvennaya literatura, 262-293.

Chumakova, T.V. (2004). Tradiczii zhenskoj svyatosti v russkoj kul'ture XIXVII vv. [The tradition of female sanctity in the Russian culture of the XIXVII centuries]. Vestnik SPbGU, t. 4, 24-30.

Dolgorukaya, N. (1913). Svoyeruchnyye zapiski knyagini Natal'i Borisovny Dolgorukoy, docheri g. fel'dmarshala grafa Borisa Petrovi [Handwritten notes of Princess Natalya Borisovna Dolgoruka, daughter of Mr. Field Marshal Count Boris Petrovich Sheremetyev]. Sankt Petersburg: Tipografiya "Sirius".

Ikonnikov, B.C. (1874). Russkaya zhenshhina nakanune reformy' Petra Velikogo $i$ posle nee [Russian woman on the eve of the reform of Peter the Great and after her]. Kiev: Tipografiya imperatorskogo universiteta. 
Ikonnikov, V.S. (1897). Znachenie czarstvovaniya Ekateriny' II [The Significance of the reign of Catherine II]. Kiev: Tipografiya imperatorskogo universiteta.

Kolesov, V.V. i Rozhdestvenskaya, V.V. (red.). Domostroy (2007). Wydanie trzecie. Leningrad: Nauka.

Likhachev, D.S. (1987). Chelovek v kul'ture Drevnej Rusi [Man in the culture of Ancient Russia] [Selected works in 3 vol.]. Leningrad: Khudozhestvennaya literatura, 3-165.

Lotman, Y.M. (1992). O semiosfere [Universe of the mind]. W: Y.M. Lotman, Izbranny'e stat'i $v$ trekh tomakh [Selected articles in 3 vol.]. T. 1. Stat'i po semiotike i topologii kul'tury'. Tallinn: Aleksandra.

Lurie, Y.S. i Rykov, J.D. (red.). (1993). Perepiska Ivana Groznogo s Andreem Kurbskim [Correspondence of Ivan The Terrible with Andrei Kurbsky]. Moscow: Nauka.

Pushkareva, N.L. (1989). Zhenshhiny' Drevnej Rusi [Women of Ancient Russia]. Moscow: My'sl'.

Pushkareva, N.L. (1996). Zhenshhiny' Rossii i Evropy' na poroge Novogo vremeni [Women of Russia and Europe on the threshold of Modern times]. Moscow: Izdatel'stvo IE'A RAN.

Romanov, B.A. (2002). Lyudi i nravy' Drevnej Rusi: Istoriko-by'tovy'e ocherki $X I-X I I I v v$. [People and customs of Ancient Russia: historical and everyday life of the XI-XIII centuries]. Moscow: Territoriya.

Shcherbatov, M.M. (1858). O povrezhdenii nravov v Rossii [On the corruption of morals in Russia]. W: „O Povrezhdenii nravov $v$ Rossii” knyazya M. Shherbatova i „Puteshestvie” A. Radishheva spredisloviem Iskandera [„,On the Corruption of morals in Russia” Prince M. Shcherbatov, and „Journey” Radishcheva A. with a Preface by Iskander]. London: Trubner \& Co, 15-114.

Slovo Daniila Zatochnika po redakcziyam XII $i$ XIII vv. $i$ ikh peredelkam [The Word of Daniel The Exile to the editors of the XII and XIII centuries and their alterations] (1932). W: Pamyatniki drevnerusskoj literatury'. T. 3 [Monuments of ancient Russian literature, vol. 3]. Leningrad: AN SSSR.

Snisarevsky, P.V. (1983). Otnoshenie k zhenshhine v pamyatnikakh russkogo srednevekov`ya (XI-XV vv.) [Attitude towards women in the monuments of the Russian middle ages (XI-XV centuries)]. W: Istoriograficheskie $i$ istoricheskie problemy 'russkoj kul'tury' [Historiographical and historical problems of Russian culture]. Moscow: Institut Istorii SSSR, AN SSSR, 26-46. Solonenko, L.V. (2006). Poe'tika drevnerusskikh zhenskikh zhitij [Poetics of old Russian women's lives] [PhD text]. Vladivostok: Dalnievostochnyj Gosudarstviennyj Universitet. 
Elena Ovchinnikova - starszy wykładowca w Zakładzie Etyki Instytutu Filozofii Uniwersytetu Państwowego w Sankt Petersburgu. Autorka ponad 90 publikacji naukowych. Absolwentka Wydziału Filozofii Państwowego Uniwersytetu w Leningradzie. Jej praca magisterska dotyczyła badań nad moralnością dekabrystów. Zainteresowania naukowe: historia rosyjskiej myśli etycznej, historia kultury rosyjskiej, koncepcje etyczne myśli rosyjskiej.

Sergey Troitskiy - dyrektor Centrum Studiów Kulturowych i Komunikacji Międzykulturowej Państwowego Uniwersytetu Pedagogicznego im. A. Herzena, Rosja, kierownik Centrum Badań nad Wykluczeniem Kulturowym i Strefami Granicznymi Instytutu Socjologii Rosyjskiej Akademii Nauk - Oddział Federalnego Centrum Socjologii Teoretycznej i Stosowanej Rosyjskiej Akademii Nauk. Starszy wykładowca w Zakładzie Filozofii i Kultury Rosyjskiej Instytutu Filozofii Uniwersytetu Państwowego w Sankt Petersburgu. Autor ponad 100 publikacji naukowych. Absolwent Wydziału Filozofii Państwowego Uniwersytetu w Petersburgu. Tematem jego pracy magisterskiej była społeczna filozofia śmiechu. Zainteresowania naukowe: historia filozofii rosyjskiej, historia i teoria kultury rosyjskiej, kultura ludowa, teoria wykluczenia kulturowego, strefy graniczne. 